\title{
Assessment of factors affecting the difficulty of caudal epidural injections in adults using ultrasound
}

\author{
Young Hoon Kim MD ${ }^{1}$, Hue Jung Park MD PhD ${ }^{1}$, Sungkun Cho $\mathrm{PhD}^{2}$, Dong Eon Moon MD PhD ${ }^{1}$
}

YH Kim, HJ Park, S Cho, DE Moon. Assessment of factors affecting the difficulty of caudal epidural injections in adults using ultrasound. Pain Res Manag 2014;19(5):275-279.

BACKGROUND: In unaided caudal epidural block (CEB), incorrect needle insertion has been reported to occur in $15 \%$ to $38 \%$ of attempts. OBJECTIVE: To statistically analyze the anatomical variables affecting difficult CEB using ultrasonographic measurement.

METHODS: Preprocedural ultrasonography was performed and the following measurements were obtained in 146 patients: the distance from the skin to the apex of the sacral hiatus; the depth of the sacral canal at the apex of the sacral hiatus; the length of the sacrococcygeal ligament between the apex of the sacral hiatus and sacral base; the distance from the skin to the apex of the sacral cornu; and the distance between the apexes of bilateral cornua. One clinician, unaware of the ultrasonographic findings, performed the injections using the landmark technique. The procedures were videotaped and were subsequently reviewed by an independent investigator.

RESULTS: The means $( \pm$ SDs) of the abovementioned measurements were $12.1 \pm 3.7 \mathrm{~mm}, 6.1 \pm 2.1 \mathrm{~mm}, 25.9 \pm 7.4 \mathrm{~mm}, 10.0 \pm 4.0 \mathrm{~mm}$ and $16.4 \pm 3.2 \mathrm{~mm}$, respectively. Injections failed in $16(11 \%)$ patients and were defined as difficult in $21(14.4 \%)$ patients. The depth of the sacral canal at the apex of sacral hiatus $(\mathrm{P}<0.001)$ and the length of the sacrococcygeal ligament between the apex of the sacral hiatus and sacral base $(\mathrm{P}=0.001)$ were significant predictors of difficult CEB. Of all patients, $85.7 \%$ and $75.2 \%$ were correctly classified as difficult or not difficult, respectively. The cutoff values of the depth of the sacral canal at the apex of the sacral hiatus and the length of the sacrococcygeal ligament between the apex of the sacral hiatus and the sacral base to predict a difficult CEB were $3.7 \mathrm{~mm}$ and $17.6 \mathrm{~mm}$, respectively.

CONCLUSIONS: Both the depth of the sacral canal at the apex of the sacral hiatus and the length of the sacrococcygeal ligament between the apex of the sacral hiatus and sacral base are significant variables affecting the difficulty of the CEB.

Key Words: Caudal epidural block; Sacrococcygeal ligament; Ultrasonography

audal epidural block (CEB) is one method of delivering medication to the epidural space used in the management of chronic low back pain and lower extremity pain (1). Successful CEB is dependent on the appropriate placement of a needle in the epidural space. The identification of the sacral hiatus is essential for the correct placement of a needle. However, anatomical variations cause difficulty in successful CEB. Difficulty is sometimes encountered in performing CEB, even when the sacral hiatus and sacral cornua are satisfactorily palpated.

Incorrect needle placement has been observed in $15 \%$ to $38 \%$ of attempts using blind or unaided techniques, even by experienced clinicians $(2,3)$. The 'whoosh' test (2), nerve stimulation (4) and fluoroscopy (5) can be used to identify the correct epidural space. Recently, the use of ultrasound guidance in CEB to position the needle in the caudal space has been reported $(3,6,7)$. Furthermore, ultrasound can be used as a screening tool for proceeding with CEB in adults (3). In that study, which involved 47 patients, there were seven caudal

\author{
L'évaluation des facteurs influant sur la \\ difficulté des injections caudales et péridurales \\ chez les adultes, à l'aide de l'échographie
}

HISTORIQUE : Lors d'un bloc caudal ou péridural (BCP) sans aide, l'insertion de l'aiguille est incorrecte dans $15 \%$ à $38 \%$ des tentatives. OBJECTIF : Effectuer une analyse statistique des variables anatomiques liées aux BCP difficiles à l'aide de mesures échographiques.

MÉTHODOLOGIE : Une échographie a été effectuée avant l'intervention et les mesures suivantes ont été prises chez 146 patients : distance entre la peau et la crête du hiatus sacré, profondeur du canal sacré à la crête du hiatus sacré, longueur du ligament sacro-coccygien entre la crête du hiatus sacré et la base du sacrum, distance entre la peau et la crête des cornes du sacrum et distance entre les crêtes des cornes bilatérales. Un clinicien qui n'avait pas vu les mesures échographiques a effectué les injections au moyen des repères anatomiques. Les interventions ont été enregistrées sur vidéo, puis examinées par un investigateur indépendant.

RÉSULTATS : Les moyennes ( \pm ÉT) des mesures précédentes étaient de $12,1 \pm 3,7 \mathrm{~mm}, 6,1 \pm 2,1 \mathrm{~mm}, 25,9 \pm 7,4 \mathrm{~mm}, 10,0 \pm 4,0 \mathrm{~mm}$ et $16,4 \pm 3,2 \mathrm{~mm}$, respectivement. Les injections ont échoué chez 16 patients (11\%) et ont été considérées comme difficiles chez 21 patients (14,4\%). La profondeur du canal sacré à la crête du hiatus sacré $(\mathrm{P}<0,001)$ et la longueur du ligament sacro-coccygien entre la crête du hiatus sacré et la base du sacrum $(\mathrm{P}=0,001)$ étaient d'importants prédicteurs d'un BCP difficile. Sur l'ensemble des patients, $85,7 \%$ et 75,2 \% étaient bien classés comme difficiles ou non, respectivement. Les valeurs seuils de la profondeur du canal sacré à la crête du hiatus sacré et de la longueur du ligament sacrococcygien entre la crête du hiatus sacré et la base du sacrum prédictives d'un BCP difficile étaient de 3,7 mm et de 17,6 mm, respectivement. CONCLUSIONS : La profondeur du canal sacré à la crête du hiatus sacré et la longueur du ligament sacro-coccygien entre la crête du hiatus sacré et la base du sacrum sont des variables significatives qui ont une incidence sur la difficulté du BCP.

epidural failures, in which the sacral canal depths were $\leq 1.6 \mathrm{~mm}$. However, apart from studies investigating the optimal angle of needle insertion based on the anatomy of the caudal space in children $(8,9)$, to our knowledge, there has been no report on which anatomical variables are statistically related to the difficulty of performing CEB. The purpose of the present study was to investigate the factors affecting difficult CEB. The present study also evaluated the cut-off values of the factors predicting difficulty.

\section{Participants}

\section{METHODS}

The study protocol was approved by the institutional review board of Seoul St Mary's Hospital of Catholic University (no. KC11OISI0688) and has also been registered with the Clinical Research Information Service of South Korea (http://cris.nih.go.kr; no. KCT0000474). The board confirmed informed consent. Patients who had a history of

\footnotetext{
${ }^{1}$ Department of Anesthesiology and Pain Medicine, School of Medicine, The Catholic University of Korea, Seoul St Mary's Hospital, Seoul;

${ }^{2}$ Department of Psychology, Chungnam National University, Daejeon, South Korea

Correspondence: Dr Dong Eon Moon, Department of Anesthesiology and Pain Medicine, School of Medicine, The Catholic University of Korea,

Seoul St Mary's Hospital, 505 Banpo-dong, Seocho-gu, Seoul 137-701, South Korea. Telephone 82-2-2258-2235 ext 6150,

fax 82-2-537-1951, e-mail demoon@catholic.ac.kr
} 

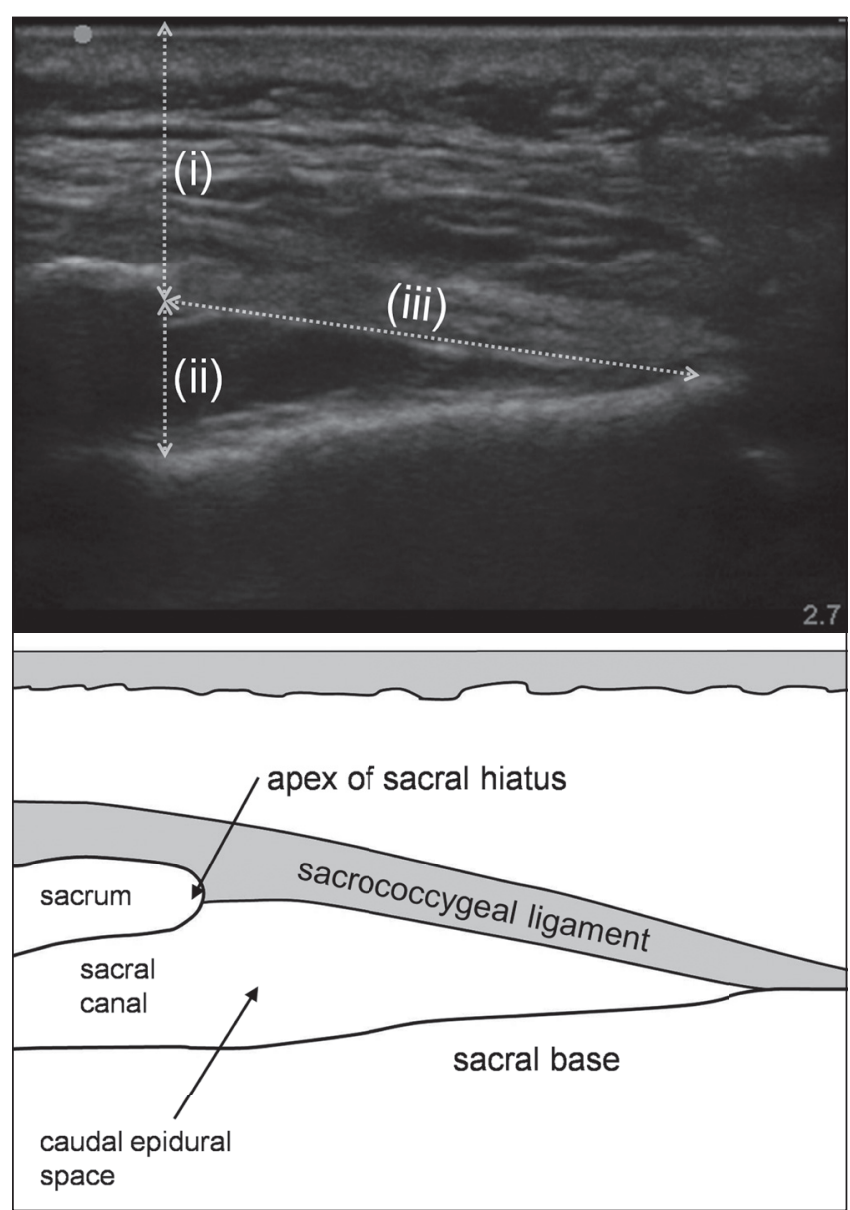

Figure 1) Longitudinal view of the sacral hiatus. The top panel is an ultrasound image showing how the distance from the skin to the apex of sacral hiatus (i), the depth of the sacral canal at the apex of sacral hiatus (ii) and the length of the sacrococcygeal ligament between the apex of sacral hiatus and sacral base (iii) were measured. The bottom panel is a schematic diagram showing the apex of the sacral hiatus, sacrococcygeal ligament, sacral canal and sacral base

coccygeal fracture or operation on the sacrococcygeal region were excluded. Four patients declined to participate, and a total of 146 patients ( 51 men and 95 women) with low back pain, sciatica or both were consecutively enrolled in the present study between September 2011 and July 2012.

\section{Preprocedural ultrasonography}

All patients underwent a preprocedural ultrasonographic scan by a researcher who was not involved in the CEB procedure and had $>6$ years' experience performing musculoskeletal ultrasonography. The SonoSite S-Nerve ultrasonography device (SonoSite Inc, USA) with a $13-6 \mathrm{MHz}$ linear-array transducer was used in the present study. The subjects were positioned prone with a pillow under their pelvis, and were required to spread their legs with the heels rotated laterally. After placing the transducer with sagittal view between the two sacral cornua, the following measurements were obtained: the distance from the skin to the apex of the sacral hiatus; the depth of the sacral canal at the apex of the sacral hiatus; and the length of the sacrococcygeal ligament between the apex of the sacral hiatus and the sacral base (Figure $1)$. The transducer was then rotated $90^{\circ}$ to examine the transverse view of the sacral cornua and the distance from the skin to the apex of the sacral cornu as well as the distance between apexes of the bilateral cornua were measured (Figure 2). Whether ossification of the sacrococcygeal ligament was observed was also recorded. All measurements were recorded in millimetres.
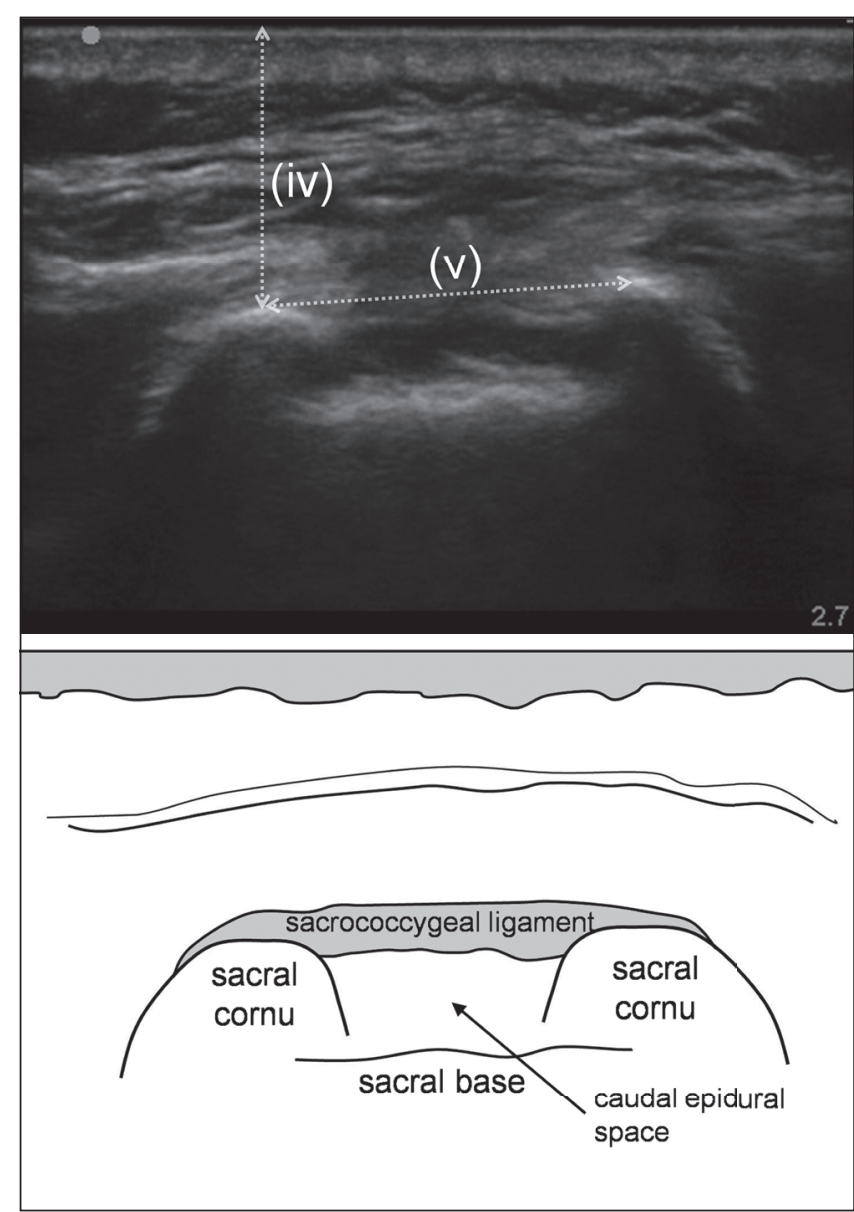

Figure 2) Transverse view of the sacral hiatus. The top panel is an ultrasound image showing how the distance from skin to the apex of sacral cornu (iv) and the distance between apices of bilateral cornua $(v)$ were measured. The bottom panel is a schematic diagram showing the sacral cornua, sacrococcygeal ligament, caudal epidural space and sacral base

\section{Procedures}

The procedural area for CEB was prepared and draped in the usual sterile fashion. Before the insertion of the needle, the subcutaneous tissue was infiltrated with $1 \%$ lidocaine. A 22 -gauge Tuohy needle was inserted into the skin and pointed toward the sacral hiatus between the sacral cornua, using a blind technique, by a physician who was unaware of the ultrasound findings and had $>10$ years' experience with CEB. When neither tissue resistance nor subcutaneous injection was noticed after injecting saline, the location of the needle was confirmed by ultrasonography. All procedures were videotaped using a video recorder (NEX-VG20 Full HD, Sony, Japan) with $1920 \times 1080$ pixel resolution. The video was reviewed by an investigator who was not involved in performing the procedure. The number of needle passes and procedure time were measured from the video analysis. Needle pass was defined as intermittent or continuous forward advancement of the Tuohy needle without withdrawing $1 \mathrm{~cm}$ or more, which resulted from bony contact or needle repositioning. Procedure time was defined as the interval between Tuohy needle insertion and the discontinuation or abandonment of the procedure. Procedure failure was defined as a CEB with an ultrasound image showing that Tuohy needle was in the subcutaneous tissue and not in the epidural space. A difficult CEB was defined as a procedure that lasted $>100 \mathrm{~s}$ and/or $>10$ needle passes were performed. The CEB was also considered to be difficult if the procedure failed. 
TABLE 1

Measured variables and performance characteristics $(n=146)$

\begin{tabular}{ll}
\hline Parameter & Mean \pm SD (range) \\
\hline Distance from the skin to the apex of sacral hiatus, $\mathrm{mm}$ & $12.1 \pm 3.7(4.1-21.8)$ \\
Depth of the sacral canal at the apex of sacral hiatus, $\mathrm{mm}$ & $6.1 \pm 2.1(1.1-12.9)$ \\
Length of the sacrococcygeal ligament between the apex of sacral hiatus and sacral base, $\mathrm{mm}$ & $25.9 \pm 7.4(7.4-49.3)$ \\
Distance from the skin to the apex of sacral cornu, $\mathrm{mm}$ & $10.0 \pm 4.0(2.3-22.5)$ \\
Distance between apexes of bilateral cornua, $\mathrm{mm}$ & $16.4 \pm 3.2(8.5-24.6)$ \\
Procedure time, $\mathrm{s}$ & $46.1 \pm 50.6(6.0-230.0)$ \\
Needle passes, $\mathrm{n}$ & $4.0 \pm 4.6(1.0-25.0)$
\end{tabular}

TABLE 2

Correlations among anatomical variables, age, sex, body mass index (BMI), ossification of the sacrococcygeal ligament and difficulty of caudal epidural block

\begin{tabular}{|c|c|c|c|c|c|c|c|c|c|c|}
\hline & & $\mathbf{i}$ & ii & iii & iv & $\mathbf{v}$ & Age & Sex & BMI & Ossification of the sacrococcygeal ligament \\
\hline Difficulty & $r$ & 0.108 & -0.463 & -0.459 & 0.049 & -0.016 & 0.001 & 0.137 & 0.061 & 0.121 \\
\hline
\end{tabular}

${ }^{*} P<0.05$. BMI Body mass index; $i$ The distance from the skin to the apex of sacral hiatus; ii The depth of the sacral canal at the apex of the sacral hiatus; iii The length of the sacrococcygeal ligament between the apex of the sacral hiatus and the sacral base; iv The distance from the skin to the apex of the sacral cornu; $r$ Pearson correlation coefficient; $v$ The distance between the apexes of the bilateral cornua

\section{Statistical analysis}

Pearson's correlation was used to assess the relationships among the difficulty in performing CEB and anatomical variables, age, sex, body mass index (BMI) and the presence of ossified sacrococcygeal ligament. In addition, logistic regression was used to predict the binomial outcome of the difficulty in performing CEB (ie, not difficult or difficult), using anatomical variables, age, sex, BMI and the presence of ossified sacrococcygeal ligament. Subsequently, discriminant function analysis (the main purpose of which is to determine which variables discriminate between two or more groups) was used to assess the adequacy of classification and to determine the cutoff values to classify the group memberships (ie, not difficult or difficult). Statistical analyses were performed using SPSS version 18.0 (IBM Corporation, USA); $\mathrm{P}<0.05$ was considered to be statistically significant.

\section{RESULTS}

Caudal epidural block failed in $16(11 \%)$ patients and was defined as difficult in $21(14.4 \%)$ patients. Four $(7.8 \%)$ of 51 men and 17 (17.9\%) of 95 women experienced a difficult CEB. All failed cases were reperformed successfully using ultrasound. The mean $( \pm$ SD) age of the patients was $57.8 \pm 14.4$ years, mean height was $160.0 \pm 9.7 \mathrm{~cm}$, mean weight was $61.0 \pm 11.7 \mathrm{~kg}$ and the mean calculated BMI was $23.7 \pm 3.4 \mathrm{~kg} / \mathrm{m}^{2}$.

Anatomical measurements and performance characteristics are described in Table 1. Ossification of the sacrococcygeal ligament was observed in $29 \%$ of the patients. In both simple correlation analysis and multivariate logistic regression analysis, two of the anatomical variables - the depth of the sacral canal at the apex of the sacral hiatus and the length of the sacrococcygeal ligament between the apex of the sacral hiatus and the sacral base - were significant predictors of difficult caudal block (Tables 2 and 3). There was no statistical correlation between the other variables and the difficulty of CEB.

Subsequently, discriminant analysis was performed using the two significant anatomical variables above, obtained in the logistic regression. Of all patients, $85.7 \%$ and $75.2 \%$ were correctly classified as difficult or not difficult, respectively. Estimated error rates were $14.3 \%$ for the difficult group and $24.8 \%$ for the not difficult group (Table 4). In addition, an additional two discriminant analyses were performed using each significant anatomical variable above, obtained in the logistic regression, to determine the cut-off values to classify the group memberships. The results showed that the cut-off values of the depth of the sacral canal at the apex of the sacral hiatus and the length of the sacrococcygeal ligament between the apex of the sacral hiatus and the sacral base were $3.7 \mathrm{~mm}$ and $17.6 \mathrm{~mm}$, respectively. Specifically, if the discriminant score of the function is greater than or equal to the cutoff, the case is classified as not difficult; if it is less than the cut-off, it is classified as difficult.

\section{DISCUSSION}

One of the causes of CEB failure is anatomical variation. Because the apex of the sacral hiatus is associated with the entrance to the sacral canal, the sacral hiatus is the most critical anatomical landmark affecting CEB. The anatomical variations of absent hiatus and complete agenesis of the sacral hiatus will lead to CEB failure (10). However, at times, clinicians experience difficulty performing CEB even though the sacral hiatus is palpated well. A narrow sacral canal makes it difficult to locate the sacral canal opening $(3,11)$. In general, we are not able to predict a narrow canal by palpation only.

Under ultrasonographic examination, the apex of the sacral hiatus, the structure of cornua, the sacrococcygeal ligament and the sacral base can be observed. Ultrasound is an effective tool for detecting anatomical variations and a screening tool for determining the success of CEB $(3,7,12)$. Therefore, the advantages of ultrasound as a screening tool can be tested if statistically significant anatomical variables are identified.

In the present study, only the depth of the sacral canal and the length of the sacrococcygeal ligament between the apex of sacral hiatus and sacral base were statistically significant variables to predict the difficulty of the CEB (Tables 2 and 3). The depth of the sacral canal at the apex of the sacral hiatus measured in our patients was similar to the findings reported in two previous studies $(3,11)$. Another study reported that four patients with failed CEB had a narrow sacral canal whose depth was $\leq 1.6 \mathrm{~mm}$ (3). The authors concluded that the incidence of failure in CEB would increase if the sacral canal depth was approximately $1.5 \mathrm{~mm}$. In the present study, however, there were several cases of failed or difficult CEB in patients whose sacral canal depth was $\geq 1.5 \mathrm{~mm}$. This implies that the depth of $1.5 \mathrm{~mm}$ may be undervalued, or there may be other important factors affecting the difficulty or failure of CEB. Based on the data in the present study, a sacral canal depth $<3.7 \mathrm{~mm}$ can lead to a difficult CEB. There were only two $(1.4 \%)$ patients whose sacral canal depth was $<2 \mathrm{~mm}$. This result was similar to the findings of another study (11); however, it cannot fully explain the causes of the failed or difficult CEB. We suggest that the decrease in the length of the sacrococcygeal ligament between the apex of the sacral hiatus and the sacral base is one variable that may contribute. Of the 17 patients who had a length of $<16.00 \mathrm{~mm}$ in the present study, 13 patients underwent a failed or difficult CEB. A short sacrococcygeal ligament, even with large sacral canal depth, will 
TABLE 3

Risk factors for difficult caudal epidural block in multivariate analysis

\begin{tabular}{lcc}
\hline \multirow{2}{*}{ Risk factors } & \multicolumn{2}{c}{ Difficult caudal epidural block } \\
\cline { 2 - 3 } i & \multicolumn{1}{c}{ OR $(95 \%$ CI) } & $\mathbf{P}$ \\
ii & $1.348(0.767-2.369)$ & 0.299 \\
iii & $0.226(0.106-0.484)$ & $<0.001^{*}$ \\
iv & $0.801(0.701-0.915)$ & $0.001^{*}$ \\
v & $0.809(0.448-1.459)$ & 0.481 \\
Age & $0.928(0.701-1.227)$ & 0.599 \\
Sex & $0.923(0.848-1.004)$ & 0.061 \\
Body mass index & $7.833(0.499-123.045)$ & 0.143 \\
Ossification of the sacrococcygeal & $1.514(0.272-8.439)$ & 0.636 \\
ligament & & \\
\hline
\end{tabular}

${ }^{*} P<0.05$. $i$ The distance from the skin to the apex of the sacral hiatus; ii The depth of the sacral canal at the apex of the sacral hiatus; iii The length of the sacrococcygeal ligament between the apex of the sacral hiatus and the sacral base; iv The distance from the skin to the apex of the sacral cornu; $v$ The distance between apexes of the bilateral cornua

\section{TABLE 4}

Classification results from discriminant function analysis*

\begin{tabular}{lccc}
\hline \multirow{2}{*}{ Difficulty } & \multicolumn{3}{c}{ Predicted group membership } \\
\cline { 2 - 4 } Not difficult & Not difficult & Difficult & Total \\
Difficult & $94(75.2)$ & $31(24.8)$ & $125(100)$ \\
\hline
\end{tabular}

*76.7\% of original grouped cases correctly classified

increase the angle of the needle insertion or make it difficult to locate the opening of the caudal epidural space. Furthermore, if there is a large ossification of the sacrococcygeal ligament, which can prohibit a needle from entering the epidural space, the space for the needle to pass through will become narrower (Figure 3). One study reported that ossification of the ligament between the sacral cornu and coccyx was observed in $14 \%$ of cadaveric cases (10). In the current study, $29 \%$ of the patients showed an ultrasonographic hyperechoic appearance, indicating ossification. However, no statistically significant correlation between the ossification of the ligament and difficulty of CEB was observed.

Obesity was not necessarily associated with difficult CEB. Six obese patients, with $\mathrm{BMI} \geq 30 \mathrm{~kg} / \mathrm{m}^{2}$, were included; however, none had thick subcutaneous fat in the sacral area, which would impede ultrasonography. A curved transducer for deeper structures was also not used in the present study. However, there was a limitation that no morbidly obese $\left(\mathrm{BMI} \geq 40 \mathrm{~kg} / \mathrm{m}^{2}\right)$ patients were included in the present study.

The distance between the apexes of the bilateral cornua was also not a statistically significant factor predictive of difficult CEB, and was wide enough for the needle to pass through. This distance measured in our patients was longer than that of other studies $(3,10,11)$. This discrepancy would be due to the difference in the definition of measurement. We used the apexes of the sacral cornua rather than the inner surfaces. In addition, as the point to be measured becomes closer to the apex of the sacral hiatus, the distance between the apexes of the bilateral cornua becomes smaller.

The current study had several limitations. Only Asian subjects were included. In a study involving white North American women, the mean depth of the sacral canal at the apex of sacral hiatus was $5 \mathrm{~mm}$ (13) compared with $4 \mathrm{~mm}$ (14) in Indian male cadavers. In the present study, the mean length of the sacrococcygeal ligament between the apex of sacral hiatus and sacral base was $25.9 \mathrm{~mm}$ compared with $34.2 \mathrm{~mm}$ (14) in Indian male cadavers. Although it was reported that there are probable racial variations in the coccygeal region $(13,15)$, the research

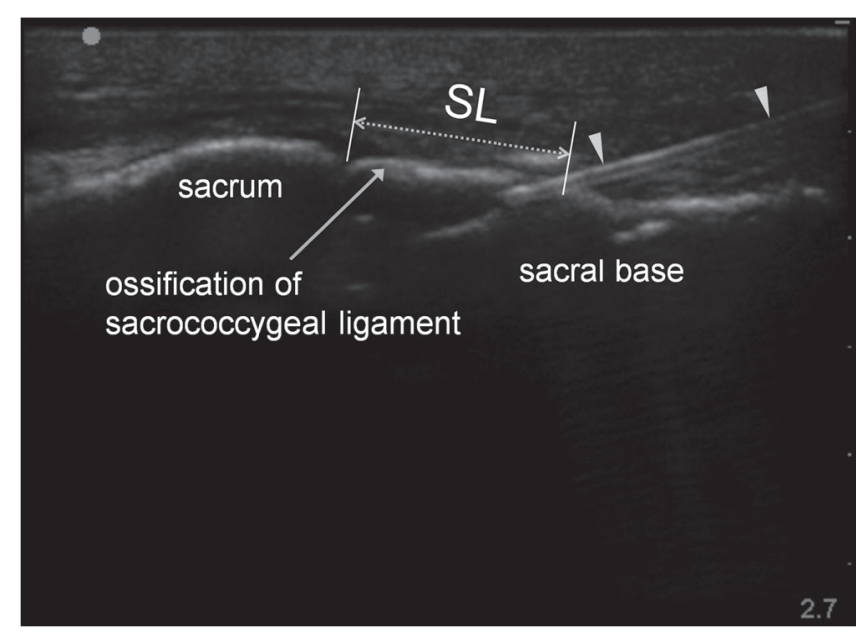

Figure 3) Ultrasonographic longitudinal image of difficult candal epidural block. Ossification of the sacrococcygeal ligament is shown. The arrowheads indicate a needle. SL Short length of the sacrococcygeal ligament between the apex of the sacral hiatus and the sacral base

investigating ethnic differences between anatomical variations and difficult CEBs is relatively limited. Hence, we cannot conclude that the results of the present study are applicable to all ethnicities.

Some concern about the ethics of the study design could be expressed. First, we primarily used a blind technique, despite our ability to use ultrasound. However, we believe that all participants agreed to the purpose and method of the present study following understanding the researcher's explanation. Second, we videotaped the procedures and reviewed the videos, which could have been leaked online or shared by individuals. We believe that there was no concern about this issue because all videos were deleted completely after review. Third, a difficult CEB was defined as a procedure that took $>100 \mathrm{~s}$ and/or $>10$ needle passes were performed, which may have caused excessive suffering among patients. All procedures were gently performed by an expert without any excessive attempts. Needle pass was defined not as withdrawing of needle tip out of the skin but as intermittent or continuous forward advancement of the needle without withdrawing $1 \mathrm{~cm}$ or more. We believe that this procedure was not unethical. Finally, all cases that failed using a blind technique were reperformed successfully using ultrasound.

Additionally, we did not verify whether inadvertent vascular injection occurred under fluoroscopy. If vascular injection had been defined as a procedure failure, the failure rate $(11 \%)$ of $\mathrm{CEB}$ in the present study may have been as high as those (15\% to $38 \%$ ) reported in other studies. The suggestion that fluoroscopy is better than ultrasonography in detecting inadvertent intravascular injection is generally accepted (12). This is one of the important limitations to an ultrasound-guided CEB.

Nonetheless, ultrasound can clearly identify the anatomical structures of the sacral hiatus. In other studies, a closed sacral canal was observed in $2 \%$ to $3 \%$ of the subjects $(3,11)$. However, no closed sacral canals were observed in the present study. As a result, we performed $100 \%$ successful CEBs by using ultrasound in the failed cases. This result adequately reflects how effectively ultrasound can be used to successfully perform CEB in a difficult case. Despite the above limitations, to our knowledge, the present study was the first to statistically analyze the anatomical variables related to difficulty in performing CEB.

\section{CONCLUSION}

The depth of the sacral canal at the apex of the sacral hiatus and the length of sacrococcygeal ligament between the apex of the sacral hiatus and the sacral base are associated with difficulty in performing CEB. 
DISCLOSURES: The authors have no conflicts of interest to declare.

\section{FUNDING SOURCES: None.}

\section{REFERENCES}

1. Conn A, Buenaventura RM, Datta S, Abdi S, Diwan S. Systematic review of caudal epidural injections in the management of chronic low back pain. Pain Physician 2009;12:109-35.

2. Lewis MP, Thomas P, Wilson LF, Mulholland RC. The 'whoosh' test. A clinical test to confirm correct needle placement in caudal epidural injections. Anaesthesia 1992;47:57-8.

3. Chen CP, Wong AM, Hsu CC, et al. Ultrasound as a screening tool for proceeding with caudal epidural injections. Arch Phys Med Rehabil 2010;91:358-63.

4. Tsui BC, Tarkkila P, Gupta S, Kearney R. Confirmation of caudal needle placement using nerve stimulation. Anesthesiology 1999;91:374-8.

5. Manchikanti L, Cash KA, Pampati V, McManus CD, Damron KS. Evaluation of fluoroscopically guided caudal epidural injections. Pain Physician 2004;7:81-92.

6. Blanchais A, Le Goff B, Guillot P, et al. Feasibility and safety of ultrasound-guided caudal epidural glucocorticoid injections. Joint Bone Spine 2010;77:440-4.
7. Chen CP, Tang SF, Hsu TC, et al. Ultrasound guidance in caudal epidural needle placement. Anesthesiology 2004;101:181-4.

8. Shin KM, Park JH, Kil HK, et al. Caudal epidural block in children: Comparison of needle insertion parallel with caudal canal versus conventional two-step technique. Anaesth Intensive Care 2010;38:525-9.

9. Park JH, Koo BN, Kim JY, et al. Determination of the optimal angle for needle insertion during caudal block in children using ultrasound imaging. Anaesthesia 2006;61:946-9.

10. Aggarwal A, Aggarwal A, Harjeet, Sahni D. Morphometry of sacral hiatus and its clinical relevance in caudal epidural block. Surg Radiol Anat 2009;31:793-800.

11. Sekiguchi M, Yabuki S, Satoh K, Kikuchi S. An anatomic study of the sacral hiatus: A basis for successful caudal epidural block. Clin J Pain 2004;20:51-4.

12. Klocke R, Jenkinson T, Glew D. Sonographically guided caudal epidural steroid injections. J Ultrasound Med 2003;22:1229-32.

13. Norenberg A, Johanson DC, Gravenstein JS. Racial differences in sacral structure important in caudal anesthesia. Anesthesiology 1979;50:549-51.

14. Aggarwal A, Kaur H, Batra YK, et al. Anatomic consideration of caudal epidural space: A cadaver study. Clin Anat 2009;22:730-7.

15. Woon JT, Stringer MD. Clinical anatomy of the coccyx: A systematic review. Clin Anat 2012;25:158-67. 


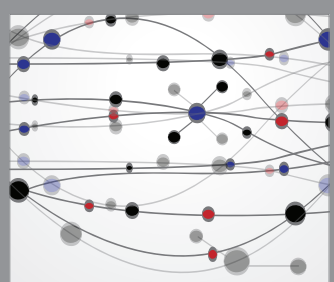

The Scientific World Journal
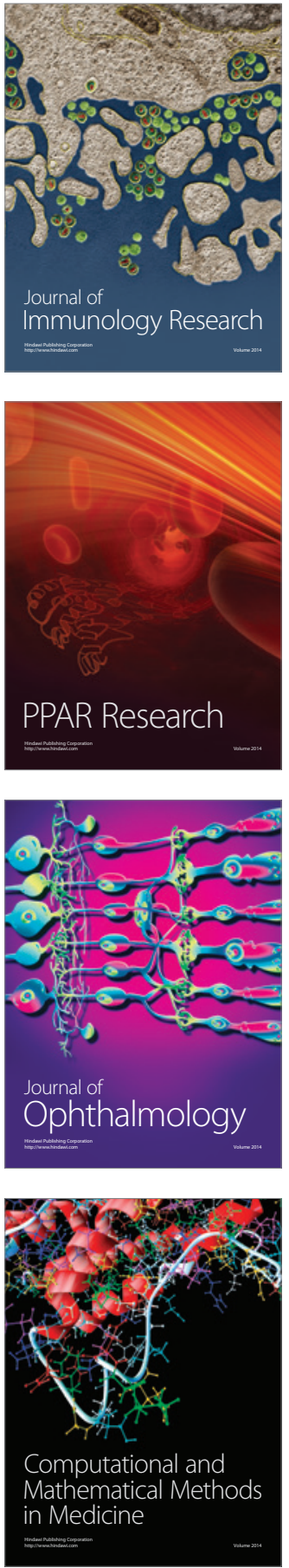

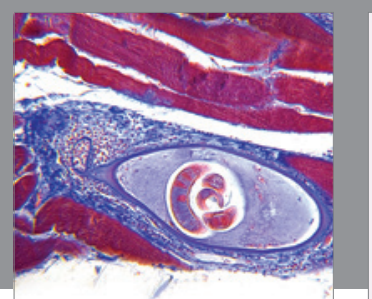

Gastroenterology Research and Practice

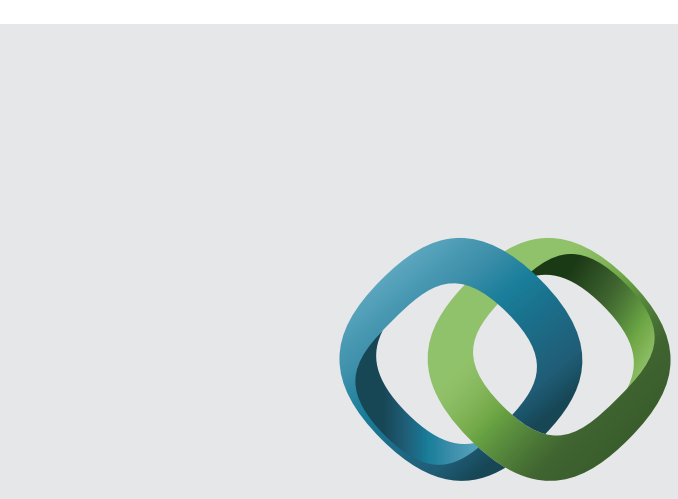

\section{Hindawi}

Submit your manuscripts at

http://www.hindawi.com
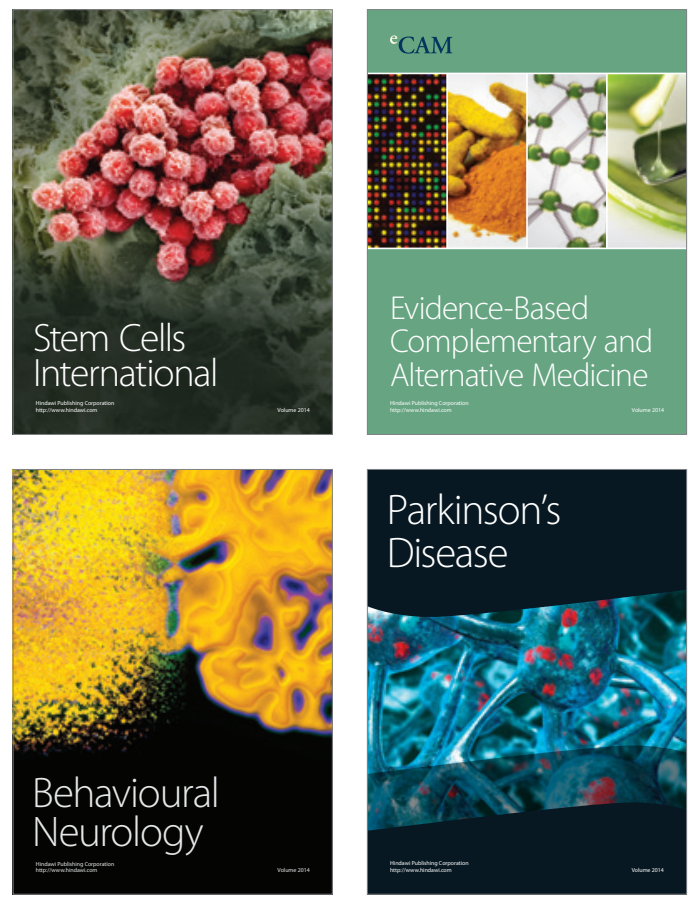
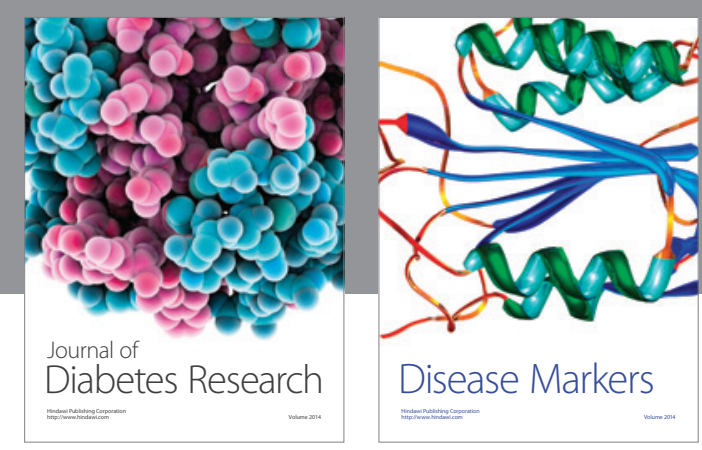

Disease Markers
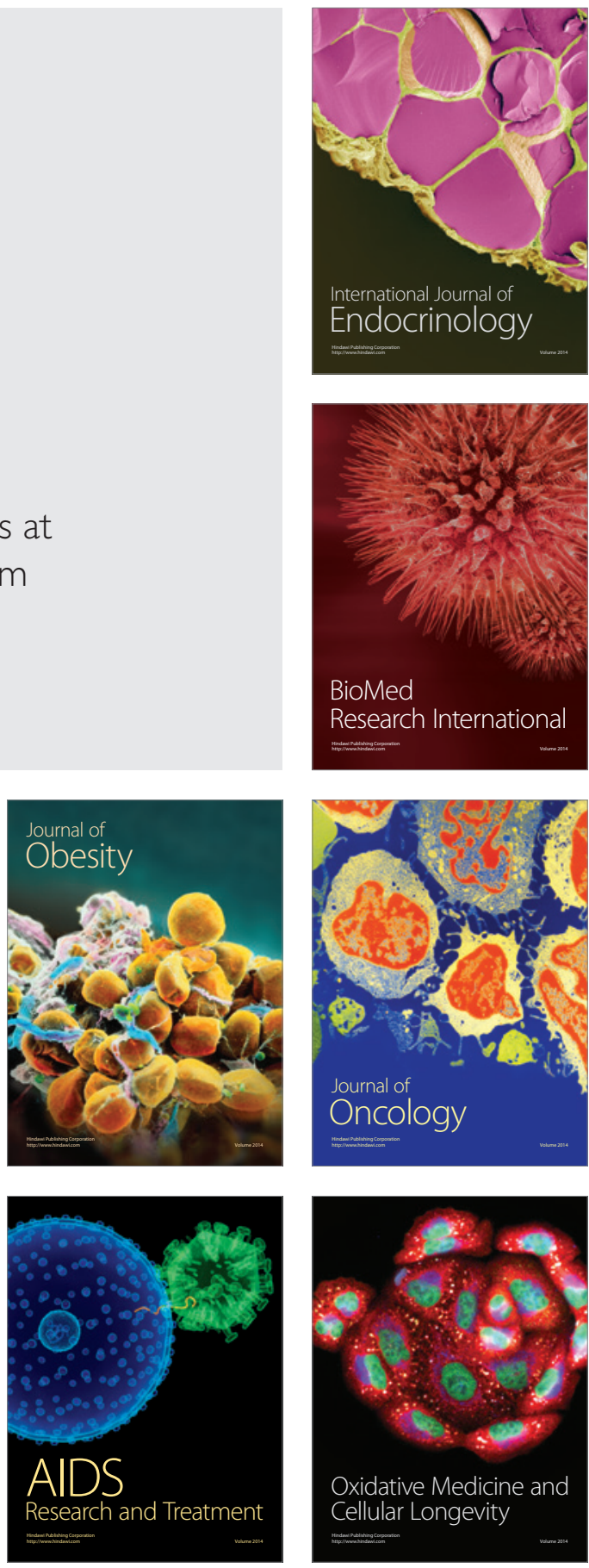